\title{
Interpretation of Offshore Crustal Movements Following the 2011 Tohoku-Oki Earthquake by the Combined Effect of Afterslip and Viscoelastic Stress Relaxation
}

\author{
Akemi Noda, ${ }^{1,4}$ (D) Tsutomu Takahama, ${ }^{1}$ Takeshi Kawasato, ${ }^{2}$ and Mitsuhiro Matsu'ura ${ }^{3}$
}

\begin{abstract}
On the 11th March 2011, a megathrust event, called the Tohoku-oki earthquake, occurred at the North American-Pacific plate interface off northeast Japan. Transient crustal movements following this earthquake were clearly observed by a dense GPS network (GEONET) on land and a sparse GPS/Acoustic positioning network on seafloor. The observed crustal movements are in accordance with ordinary expectations on land, but not on seafloor; that is, slowly decaying landward movements above the main rupture area and rapidly decaying trench-ward movements in its southern extension. To reveal the cause of such curious offshore crustal movements, we analyzed the coseismic and postseismic GPS array data on land with a sequential stepwise inversion method considering viscoelastic stress relaxation in the asthenosphere, and obtained the following results: The afterslip of the Tohoku-oki earthquake rapidly proceeds for the first 1 year on a high-angle downdip extension of the main rupture, which occurred on the low-angle offshore plate interface. The theoretical patterns of seafloor horizontal movements due to the afterslip and the viscoelastic relaxation of coseismic stress changes in the asthenosphere are essentially different both in space and time; inshore trench-ward movements and offshore landward movements for the afterslip, while overall landward movements for the viscoelastic stress relaxation. General agreement between the computed horizontal movements and the GPS/Acoustic observations demonstrates that the postseismic curious offshore crustal movements can be ascribed to the combined effect of afterslip on a high-angle downdip extension of the main rupture and viscoelastic stress relaxation in the asthenosphere.
\end{abstract}

Key words: The 2011 Tohoku-oki earthquake, postseismic crustal movements, GPS data, GPS/Acoustic data, afterslip, viscoelastic stress relaxation.

1 Kozo Keikaku Engineering Inc., Nakano-ku, Tokyo 1640011, Japan. E-mail: noda@bosai.go.jp

2 The Japan Atomic Power Company, Chiyoda-ku, Tokyo 101-0053, Japan.

3 Institute of Statistical Mathematics, Tachikawa, Tokyo 190-8562, Japan.

4 Present Address: National Research Institute for Earth Science and Disaster Resilience, 3-1 Tennodai, Tsukuba, Ibaraki 305-0006, Japan.

\section{Introduction}

The 2011 Tohoku-oki earthquake, a megathrust event occurred at the North American-Pacific plate interface, brought about not only coseismic but also postseismic crustal movements in an extensive region of northeast Japan. The postseismic transient crustal movements were observed by a dense GPS network (GEONET) on land, operated by Geospatial Information Authority of Japan (GSI), and a sparse GPS/ Acoustic positioning network on seafloor, operated by Japan Coast Guard (JCG). Figure 1 shows the postseismic horizontal displacements for the first 3 years together with the coseismic displacements. For the coseismic displacements in Fig. 1a, the GPS/Acoustic observations on seafloor (Sato et al. 2011) are consistent in sense (trench-ward) with the GPS observations on land. However, for the postseismic crustal movements in Fig. 1b, they are not consistent with each other. The GPS observations show overall trench-ward movements, whereas the GPS/Acoustic observations (Watanabe et al. 2014) show landward movements above the main rupture area and trench-ward movements in its southern extension. In addition, the timeseries data of GPS/Acoustic station coordinates (Watanabe et al. 2014) show that the characteristic decay time of the former landward movements is much longer than that of the latter trench-ward movements.

The cause of the postseismic crustal movements is considered to be afterslip at the plate interface and viscoelastic stress relaxation in the asthenosphere. First, using an elastic half-space model, namely ignoring the effect of viscoelastic stress relaxation in the asthenosphere, Ozawa et al. (2012) and Perfettini and Avouac (2014) estimated afterslip distribution from the postseismic GPS data on land for almost the 


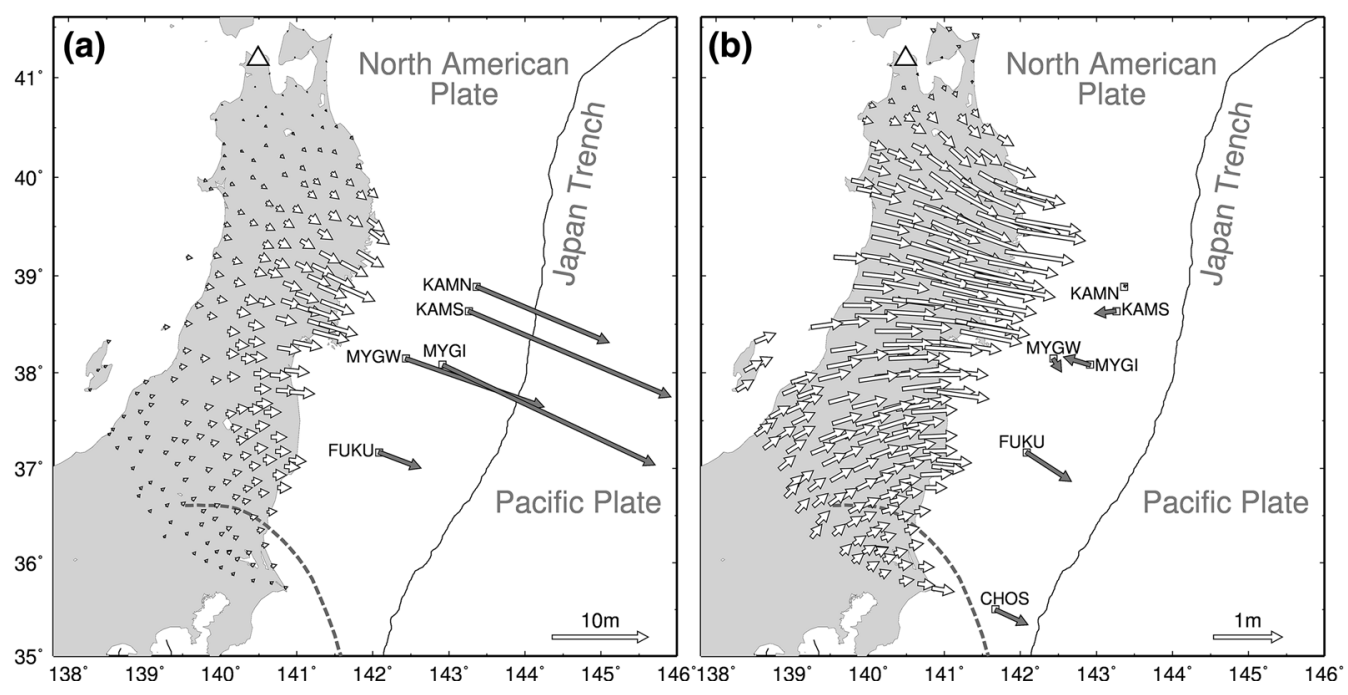

Figure 1

Coseismic and postseismic horizontal displacements associated with the 2011 Tohoku-oki earthquake. a Coseismic displacements on land (white arrows) and seafloor (gray arrows). b Postseismic displacements on land (white arrows) and seafloor (gray arrows) for the first 3 years following the main shock. The white triangle represents the reference point (GPS station 960534) to plot the displacement vectors on land. The gray broken line indicates the northeastern margin of the Philippine Sea plate overriding the Pacific plate. The GPS/Acoustic station codes, KAMN, KAMS, MYGI, MYGW, FUKU, and CHOS, are the abbreviations of Kamaishi North, Kamaishi South, Miyagi, Miyagi West, Fukushima, and Choshi, respectively

same period (the first 7 and 9 months, respectively), though the results are totally different. Then, Hashima et al. (2014) and Diao et al. (2014) demonstrated the importance of the contribution of viscoelastic stress relaxation to the postseismic crustal movements through a forward numerical simulation of co- and post-seismic internal deformation and a comparison of the inversion results of postseismic GPS data with a simple afterslip model and a combined afterslip-viscoelastic relaxation model, respectively. Using the combined afterslipviscoelastic relaxation model, Yamagiwa et al. (2015) estimated coseismic slip and afterslip distributions simultaneously from the whole data set of GPS and GPS/Acoustic observations at and after the Tohoku-oki earthquake.

On the other hand, to explain the postseismic curious seafloor movements, Sun et al. (2014) innovated a finite element model with complex rheological structure. Given the coseismic slip distribution by Iinuma et al. (2012) and the afterslip distribution by Ozawa et al. (2012), they tried to tune the viscosity parameters but could not explain the postseismic seafloor movements at two GPS/Acoustic stations off Iwate and Fukushima. Sun and Wang (2015) resolved this problem by introducing the shallow afterslip areas off Iwate and Fukushima. Using a finite element plate-subduction model, Suito (2017) examined individually the contributions of viscoelastic relaxation in the mantle wedge and the oceanic mantle to the postseismic crustal deformation. $\mathrm{Hu}$ et al. (2016) modeled afterslip as transient deformation in a thin weak shear zone with Burgers rheology distributed along the plate interface. Given the coseismic slip distribution by Iinuma et al. (2012), they tried to tune the viscosity parameters of a finite element plate-subduction model so as to explain the observed postseismic crustal movements in northeast Japan.

In this study, to reveal the cause of curious seafloor movements after the 2011 Tohoku-oki earthquake, we analyze the coseismic and postseismic GPS data on land with a sequential stepwise inversion method considering viscoelastic stress relaxation in the asthenosphere. First, we explain the sequential method of stepwise inversion. Then, we estimate the spatiotemporal distribution of afterslip together with the coseismic slip distribution. Finally, 
from the estimated results, we compute the horizontal movements due to afterslip and viscoelastic stress relaxation, and compare them with the offshore GPS/ Acoustic observations.

\section{The Method of Inversion Analysis}

Interplate megathrust events, such as the 2011 Tohoku-oki earthquake, generally cause large stress concentrations at the tips of main ruptures and nonnegligible stress changes in not only the elastic lithosphere but also the viscoelastic asthenosphere. The stress concentrations are eventually released by the occurrence of aftershocks in a shallow brittle zone and the progress of afterslip in a deep brittle-ductile transition zone. The stress changes in the asthenosphere vanish sooner or later because of their viscoelastic relaxation. Crustal responses to the afterslip and the viscoelastic relaxation are different both in space and time. So, given proper plate interface geometry and proper crust-mantle rheological structure, we can estimate spatiotemporal afterslip distribution together with coseismic slip distribution from observed co- and post-seismic crustal movements using a sequential method of stepwise inversion.

\subsection{GPS Time-Series Data}

As the co- and post-seismic crustal movement data of the $\mathrm{M}_{\mathrm{w}} 9.0$ Tohoku-oki event, we use daily horizontal coordinates of GPS stations (GEONET F3Solution) in northeast Japan (Fig. 1) for the period of 3.5 years from just before the main rupture on the 11th March 2011. The vertical components would also provide some additional information to estimate afterslip distribution, if the structure model used for inversion analysis is sufficiently accurate. However, there exists a significant systematic discrepancy between the actual structure and our structure model (a standard elastic-viscoelastic layered half-space model), which will cause a bias in the estimation of afterslip distribution. As demonstrated by Muto et al. (2016), for example, the vertical components are much sensitive to the structural discrepancy in comparison with the horizontal components, and so we did not use the vertical components in the present analysis.

To separate the crustal movements coming from the coseismic slip, afterslip and viscoelastic relaxation from the GPS time-series data, we fit a parametric model:

$$
\begin{aligned}
d_{i}(t)= & a^{i}+b^{i} t+\sum_{q=1}^{Q} c_{q}^{i} \sin (2 \pi q t)+\sum_{q=1}^{Q} c_{q}^{\prime i} \cos (2 \pi q t) \\
& +\sum_{r=1}^{R} s_{r}^{i} H\left(t-T_{r}\right)+s_{0}^{i} H\left(t-T_{0}\right) \\
& +\sum_{j=1}^{3} g_{j}^{i}\left[1-e^{-\left(t-T_{0}\right) / \tau_{j}}\right] H\left(t-T_{0}\right) \quad(i=1,2)
\end{aligned}
$$

to the time-series of each horizontal coordinate component ( $i=1$ or 2$)$ at every GPS station. Here, the first term on the right side of Eq. (1) is an adjustable constant, the second term is a secular trend determined from interseismic GPS data, the third and fourth terms are the seasonal variations with periods less than or equal to 1 year, the fifth term is coseismic steps associated with intraplate aftershocks at $t=T_{r}$ $(r=1, \ldots, R)$, and the last two terms represent the crustal movements coming from the coseismic slip at $t=T_{0}$ and the subsequent afterslip and viscoelastic stress relaxation.

Given a linear trend $b^{i}$ determined from GPS time-series data for an interseismic period (March 1998-February 2008), we estimated the optimum values of the adjustable parameters, $a^{i}, c_{q}^{i}, c_{q}^{\prime}, s_{r}^{i}, s_{0}^{i}$, and $g_{j}^{i}$, in Eq. (1) for each coordinate component at every GPS station with the least-squares method. Here, we chose the appropriate number of $Q$ with Akaike's Information Criterion (AIC; Akaike 1974). As for the three relaxation time constants $\left(\tau_{1}, \tau_{2}\right.$ and $\tau_{3}$ ), assuming their orders to be $10^{-2}, 10^{-1}$ and $10^{0}$ year, we numerically searched their appropriate values that minimize the total variance of misfits. After the optimization of adjustable parameters, we pick out the last two terms in Eq. (1) as the crustal movements coming from the coseismic slip, afterslip and viscoelastic relaxation: 


$$
\begin{aligned}
\hat{d}_{i}(t) & =\hat{s}_{0}^{i} H\left(t-T_{0}\right) \\
+ & \sum_{j=1}^{3} \hat{g}_{j}^{i}\left[1-e^{-\left(t-T_{0}\right) / \tau_{j}}\right] H\left(t-T_{0}\right) \quad(i=1,2) .
\end{aligned}
$$

For instance, the white vectors in Figs. 1a, b show the coseismic and postseismic displacements of the 2011 Tohoku-oki earthquake reproduced from only the second-to-last and last terms in Eq. (1), namely the first and second terms on the right side of Eq. (2), respectively. It should be noted that the coseismic displacements in Fig. 1a contain some displacements due to the interplate aftershocks occurred on the 11th and 12th March 2011, though their contribution is not significant. Similarly, the postseismic displacements in Fig. 1b contain some displacements due to the interplate aftershocks occurred after the 12th March 2011.

Following Noda et al. (2013), we transform the reproduced GPS horizontal displacements in Eq. (2) into the average horizontal strains of triangular elements composed of adjacent three GPS stations. We constructed the optimum triangular mesh from the GPS stations with the method of Delaunay triangulation as shown in Fig. 2a. According to Ohzono et al. (2012) and Takada and Fukushima (2013), some volcanic regions along the backbone range in northeast Japan have been subjected to abnormal inelastic deformation after the Tohoku-oki earthquake. So, we reduced the weights of strain data corresponding to these regions (the black triangles in Fig. 2a) to one-tenth of those for the others.

\subsection{Model Setting}

In northeast Japan, the Pacific (PAC) plate is descending beneath the North American (NAM) plate as shown in Fig. 1. In the south of this region, the Philippine Sea (PHS) plate is descending beneath the NAM plate and running on the PAC plate at its northeastern margin. In Fig. 2b, the 3-D geometry of the NAM-PAC plate interface is shown by the iso-depth contours (Hashimoto et al. 2004). We represent the spatiotemporal fault-slip distribution $\mathbf{w}(\boldsymbol{\eta}, t)$ on the NAM-PAC plate interface $\Sigma(\boldsymbol{\eta})$ by the superposition of known basis functions $S_{i j}(\boldsymbol{\eta})$ in space and $T_{k}(t)$ in time. Specifically, for each of the orthogonal components of fault-slip vector, the spatial distribution is represented by the superposition of 917 normalized bicubic Bsplines, $S_{i j}(\boldsymbol{\eta})=B_{i}\left(\eta_{1}\right) B_{j}\left(\eta_{2}\right)$, with the local supports of $16 \mathrm{~km}$ both in orthogonal directions as shown in Fig. 2b. On the other hand, the temporal distribution is simply represented by the superposition of Heaviside functions, $T_{k}(t)=H(t-k \Delta t)$, with the time lag of $k \Delta t$ $(k=1, \ldots, K)$. To sum up, the spatiotemporal faultslip distribution is formally represented as:

$w\left(\eta_{1}, \eta_{2}, t\right)=\sum_{i=1}^{I} \sum_{j=1}^{J} \sum_{k=0}^{K} a_{i j k} B_{i}\left(\eta_{1}\right) B_{j}\left(\eta_{2}\right) H(t-k \Delta t)$,

where $a_{i j k}$ are the unknown coefficients to be determined from the GPS data, and $I, J$ and $K$ denote the numbers of basis functions, $B_{i}\left(\eta_{1}\right), B_{j}\left(\eta_{2}\right)$ and $H(t-k \Delta t)$, used for representing the spatiotemporal fault-slip distribution.

As for the crust-mantle rheological structure, on the basis of a study on coseismic and postseismic crustal movements by Matsu'ura and Iwasaki (1983), we use a standard elastic-viscoelastic layered halfspace model consisting of a $60 \mathrm{~km}$-thick elastic surface layer and a Maxwell-type viscoelastic substratum with the viscosity of $1 \times 10^{19} \mathrm{~Pa} \mathrm{~s}$ (Table 1). The thickness of elastic surface layer and the viscosity of viscoelastic substratum are almost the same as those used in the preceding studies: e.g., $50 \mathrm{~km}$ and $2 \times 10^{19} \mathrm{~Pa} \mathrm{~s}$ for Diao et al. (2014); $50 \mathrm{~km}$ and $9 \times 10^{18} \mathrm{~Pa}$ s for Yamagiwa et al. (2015).

\subsection{Observation Equations}

Given a spatiotemporal fault-slip distribution $w(\boldsymbol{\eta}, t)$ for $t \geq 0$ on a plate interface $\Sigma(\boldsymbol{\eta})$, we can generally represent the quasi-static horizontal displacements $u_{i}(\mathbf{x}, t)$ due to the fault slip motion as:

$$
\begin{aligned}
& u_{i}(\mathbf{x}, t)=\int_{0}^{t} d \tau \int_{\Sigma} U_{i}(\mathbf{x}, t-\tau ; \boldsymbol{\eta}, 0) \dot{w}(\boldsymbol{\eta}, \tau) d \boldsymbol{\eta} \\
& \quad(i=1,2) .
\end{aligned}
$$

Here, $U_{i}(\mathbf{x}, t ; \boldsymbol{\eta}, \tau)$ denote the quasi-static displacement responses at the surface of an elasticviscoelastic layered half-space under gravity to a unit step slip at the plate interface, and the dot indicates differentiation with respect to time $t$. The concrete expressions of the quasi-static displacement 

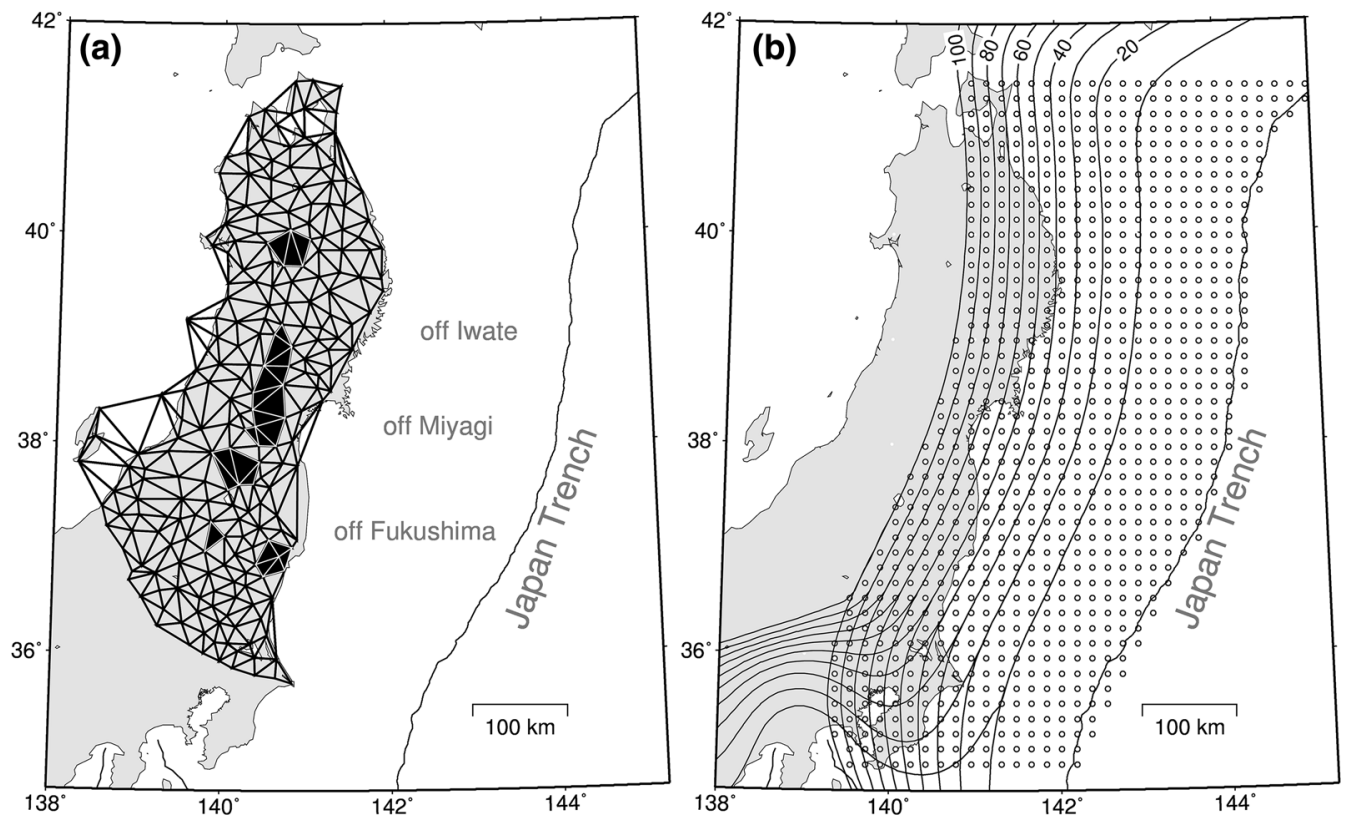

Figure 2

GPS triangular elements and model setting. a The triangle network of GPS stations, determined by the Delaunay triangulation. The weight of strain data for the black triangle elements is taken to be one-tenth of those for the other triangle elements. b The model region used for inversion analysis. The circles indicate the peak points of bicubic B-splines distributed on the NAM-PAC plate interface. The iso-depth contours at the interval of $10 \mathrm{~km}$ represent the depth to the plate interface from the solid earth surface (Hashimoto et al. 2004)

Table 1

The structural parameters of the elastic-viscoelastic layered half-space model

\begin{tabular}{llllll}
\hline & Thickness $(\mathrm{km})$ & Density $\left(\mathrm{kg} / \mathrm{m}^{3}\right)$ & Rigidity $(\mathrm{GPa})$ & Bulk modulus $(\mathrm{GPa})$ & Viscosity $(\mathrm{Pa} \mathrm{s})$ \\
\hline Lithosphere & 60 & 3000 & 40.0 & 66.7 & $\infty$ \\
Asthenosphere & $\infty$ & 3400 & 60.0 & 130.0 & $1 \times 10^{19}$ \\
\hline
\end{tabular}

responses are given in Fukahata and Matsu'ura (2006), for example. From Eq. (4), Noda et al. (2013) derived the expressions of quasi-static surface displacements at $\left(t=T_{0}\right)$ and after $\left(t=t^{\prime}+T_{0} ; t^{\prime}>0\right)$ the coseismic slip as:

$$
\begin{aligned}
& u_{i}\left(\mathbf{x}, t^{\prime}+T_{0}\right)=\left(t^{\prime}+T_{0}\right) \int_{\Sigma} U_{i}^{\infty}(\mathbf{x} ; \boldsymbol{\eta}) V_{p l}(\boldsymbol{\eta}) d \boldsymbol{\eta} \\
& \quad-\left(t^{\prime}+T_{0}\right) \int_{\Sigma_{S}} U_{i}^{\infty}(\mathbf{x} ; \boldsymbol{\eta}) \dot{w}_{s}(\boldsymbol{\eta}) d \boldsymbol{\eta} \\
& \quad+\int_{\Sigma_{S}} U_{i}\left(\mathbf{x}, t^{\prime} ; \boldsymbol{\eta}, 0\right) w_{c}(\boldsymbol{\eta}) d \boldsymbol{\eta} \\
& \quad+\int_{0^{+}}^{t^{\prime}} d \tau \int_{\Sigma_{S}} U_{i}\left(\mathbf{x}, t^{\prime}-\tau ; \boldsymbol{\eta}, 0\right) \dot{w}_{a}\left(\boldsymbol{\eta}, \tau+T_{0}\right) d \boldsymbol{\eta} .
\end{aligned}
$$

Here, $U_{i}^{\infty}(\mathbf{x} ; \boldsymbol{\eta}) \equiv U_{i}(\mathbf{x}, t \rightarrow \infty ; \boldsymbol{\eta}, 0) \quad$ denote the completely relaxed displacement responses to a unit step slip. The first and second terms on the right side of Eq. (5) represent the surface displacements due to steady slip at a plate convergence rate $V_{p l}(\boldsymbol{\eta})$ over the whole plate interface $\Sigma(\boldsymbol{\eta})$ and steady slip-deficit at the rate of $\dot{w}_{s}(\boldsymbol{\eta})$ in a seismogenic region $\Sigma_{S}(\boldsymbol{\eta})$, respectively. The third and fourth terms represent the viscoelastic responses (instantaneous elastic response and transient response due to stress relaxation in the asthenosphere) to the coseismic slip $w_{c}(\boldsymbol{\eta})$ and the subsequent afterslip $w_{a}(\boldsymbol{\eta}, t)$, respectively.

In this study, the first and second terms in Eq. (5) are replaced with the secular trend determined from GPS time-series data for an interseismic period. Then, we can relate the spatiotemporal fault-slip distributions at and after the 2011 Tohoku-oki earthquake: 


$$
\begin{gathered}
w\left(\boldsymbol{\eta}, t^{\prime}+T_{0}\right)=w_{c}(\boldsymbol{\eta}) H\left(t^{\prime}\right)+\int_{0^{+}}^{t^{\prime}} \dot{w}_{a}\left(\boldsymbol{\eta}, \tau+T_{0}\right) d \tau \\
t^{\prime} \geq 0
\end{gathered}
$$

to the reproduced GPS time-series data in Eq. (2) through the modified expression of Eq. (5),

$$
\begin{aligned}
u_{i}^{\prime}\left(\mathbf{x}, t^{\prime}\right. & \left.+T_{0}\right)=\int_{\Sigma_{S}} U_{i}\left(\mathbf{x}, t^{\prime} ; \boldsymbol{\eta}, 0\right) w_{c}(\boldsymbol{\eta}) d \boldsymbol{\eta} \\
& +\int_{0^{+}}^{t^{\prime}} d \tau \int_{\Sigma_{S}} U_{i}\left(\mathbf{x}, t^{\prime}-\tau ; \boldsymbol{\eta}, 0\right) \dot{w}_{a}\left(\boldsymbol{\eta}, \tau+T_{0}\right) d \boldsymbol{\eta} .
\end{aligned}
$$

As mentioned in Sect. 2.2, we represent the temporal variation of fault slip in Eq. (6) by the superposition of Heaviside functions $H(t-k \Delta t)$ with the time lag of $k \Delta t(k=1, \ldots, K)$ as:

$$
\begin{gathered}
w\left(\boldsymbol{\eta}, t^{\prime}+T_{0}\right)=\sum_{k=0}^{K} \Delta w_{k}(\boldsymbol{\eta}) H\left(t^{\prime}-k \Delta t\right) \\
0 \leq t^{\prime} \leq K \Delta t
\end{gathered}
$$

with

$$
\begin{aligned}
& \Delta w_{0}(\boldsymbol{\eta})=w_{c}(\boldsymbol{\eta}), \\
& \Delta w_{k}(\boldsymbol{\eta})=\int_{(k-1) \Delta t}^{k \Delta t} \dot{w}_{a}\left(\boldsymbol{\eta}, \tau+T_{0}\right) d \tau \quad(k=1, \ldots, K) .
\end{aligned}
$$

Here, it should be noted that $\Delta w_{k}(\boldsymbol{\eta})$ means the total slip during the $k$-th time step. Then, rewriting Eq. (7) as:

$$
\begin{aligned}
u_{i}^{\prime}\left(\mathbf{x}, t^{\prime}+T_{0}\right)= & \sum_{k=0}^{K} H\left(t^{\prime}-k \Delta t\right) \\
& \times \int_{\Sigma_{S}} U_{i}\left(\mathbf{x}, t^{\prime}-k \Delta t ; \boldsymbol{\eta}, 0\right) \Delta w_{k}(\boldsymbol{\eta}) d \boldsymbol{\eta} \\
& 0 \leq t^{\prime} \leq K \Delta t,
\end{aligned}
$$

we obtain the following observation equations for each GPS station at $\mathbf{x}=\mathbf{x}_{p}(p=1, \ldots, N)$ :

$$
\begin{aligned}
& \hat{d}_{i}\left(\mathbf{x}_{p}, t^{\prime}+T_{0}\right)=\sum_{k=0}^{K} H\left(t^{\prime}-k \Delta t\right) \\
& \times \int_{\Sigma_{S}} U_{i}\left(\mathbf{x}_{p}, t^{\prime}-k \Delta t ; \boldsymbol{\eta}, 0\right) \Delta w_{k}(\boldsymbol{\eta}) d \boldsymbol{\eta}+e_{i} \\
& \quad 0 \leq t^{\prime} \leq K \Delta t .
\end{aligned}
$$

Here, $e_{i}$ are data errors, which are assumed to be Gaussian with zero mean and variance $\sigma^{2}$, and $\Delta w_{k}(\boldsymbol{\eta})$ should be read as either component of slip vector on $\Sigma(\boldsymbol{\eta})$.

\subsection{Sequential Stepwise Inversion}

To solve the observation equations for the faultslip increments $\Delta w_{k}(\boldsymbol{\eta})$, we use the following sequential method of stepwise inversion. The observation equations at the initial time step $(K=0)$ give a usual inverse problem of estimating the coseismic slip distribution $\Delta w_{0}(\boldsymbol{\eta})$ from the coseismic displacements $\hat{d}_{i}\left(\mathbf{x}_{p}, T_{0}^{+}\right)$:

$$
\hat{d}_{i}\left(\mathbf{x}_{p}, T_{0}^{+}\right)=\int_{\Sigma_{S}} U_{i}\left(\mathbf{x}_{p}, 0^{+} ; \boldsymbol{\eta}, 0\right) \Delta w_{0}(\boldsymbol{\eta}) d \boldsymbol{\eta}+e_{i} .
$$

In general, at the time step of $K(\geq 1)$, Eq. (12) can be written as:

$$
\begin{array}{r}
\hat{d}_{i}\left(\mathbf{x}_{p}, K \Delta t+T_{0}\right)-\sum_{k=0}^{K-1} \int_{\Sigma_{S}} U_{i}\left(\mathbf{x}_{p},(K-k) \Delta t ; \boldsymbol{\eta}, 0\right) \Delta w_{k}(\boldsymbol{\eta}) d \boldsymbol{\eta} \\
=\int_{\Sigma_{S}} U_{i}\left(\mathbf{x}_{p}, 0^{+} ; \boldsymbol{\eta}, 0\right) \Delta w_{K}(\boldsymbol{\eta}) d \boldsymbol{\eta}+e_{i} .
\end{array}
$$

Here, it should be noted that the second term on the left side of the above equation is known as the results of the sequential inversion at the previous time steps from 0 to $K-1$. So, we can also treat Eq. (14) as a simple inverse problem of estimating the fault-slip increment $\Delta w_{K}(\boldsymbol{\eta})$ at the $K$-th time step.

Lubis et al. (2013) have also used a similar sequential procedure to estimate afterslip distribution following the 2007 southern Sumatra earthquake $\left(\mathrm{M}_{\mathrm{w}} 8.5\right)$ from postseismic GPS data. However, the sequential procedure described above has a weak point that the misfits between the data and the theoretical values at one time step are carried over 
into the next time step. To overcome this weak point, we modify Eq. (14) by taking difference between the observation equations at the $K$-th time step and the $(K-1)$-th time step as

$$
\begin{aligned}
& \Delta \hat{d}_{i}\left(\mathbf{x}_{p}, K \Delta t+T_{0}\right) \\
& \quad-\sum_{k=0}^{K-1} \int_{\Sigma_{S}} \Delta U_{i}\left(\mathbf{x}_{p},(K-k) \Delta t ; \boldsymbol{\eta}, 0\right) \Delta w_{k}(\boldsymbol{\eta}) d \boldsymbol{\eta} \\
& =\int_{\Sigma_{S}} U_{i}\left(\mathbf{x}_{p}, 0^{+} ; \boldsymbol{\eta}, 0\right) \Delta w_{K}(\boldsymbol{\eta}) d \boldsymbol{\eta}+e_{i}
\end{aligned}
$$

with

$$
\begin{aligned}
& \begin{aligned}
\Delta \hat{d}_{i}\left(\mathbf{x}_{p}, K \Delta t+T_{0}\right)= & \hat{d}_{i}\left(\mathbf{x}_{p}, K \Delta t+T_{0}\right) \\
& -\hat{d}_{i}\left(\mathbf{x}_{p},(K-1) \Delta t+T_{0}\right),
\end{aligned} \\
& \begin{aligned}
& \Delta U_{i}\left(\mathbf{x}_{p},(K-k) \Delta t\right.; \boldsymbol{\eta}, 0)=U_{i}\left(\mathbf{x}_{p},(K-k) \Delta t ; \boldsymbol{\eta}, 0\right) \\
& \quad-U_{i}\left(\mathbf{x}_{p},(K-k-1) \Delta t ; \boldsymbol{\eta}, 0\right) .
\end{aligned}
\end{aligned}
$$

At each time step, following Noda et al. (2013), we transformed the observation equations for horizontal displacements into those for horizontal strains. In the method of strain data inversion, the covariance matrix of data errors is expressed in the following form:

$$
\sigma^{2} \mathbf{E}=\sigma^{2}\left(\mathbf{R R}^{\mathrm{T}}+c^{2} \mathbf{D}\right),
$$

where $\sigma^{2}$ is an unknown scale factor to be determined through the inversion analysis of observed data, $\mathbf{R}$ is a matrix to transform horizontal displacement vectors into average strain tensors for individual triangle elements, and $\mathbf{D}$ is a diagonal matrix specifying the relative weight of individual strain data. The first and second terms on the right side of Eq. (18) correspond to random and systematic errors, respectively. The relative weight of systematic errors to random errors is controlled by $c^{2}$. We determined the appropriate value of $c^{2}$ so that the optimum value of $\sigma^{2}$ accords with the variance of random noises in the GPS timeseries data for each time step. Then, we constructed a Bayesian model with direct prior constraints on the fault-slip components perpendicular to the direction of plate convergence and indirect prior constraints on the roughness of fault-slip distribution. The relative weights of the direct and indirect prior constraints to the observed data are objectively determined with
Akaike's Bayesian Information Criterion (ABIC; Akaike 1980). Further details about the practical algorithm of Bayesian inversion analysis are given in Matsu'ura et al. (2007) and Noda et al. (2013).

\section{Spatiotemporal Distribution of Afterslip}

Applying the sequential method of stepwise inversion described in Sect. 2.4 to the reproduced GPS timeseries data, we estimated the spatiotemporal distribution of afterslip together with the spatial distribution of coseismic slip. In the present analysis, the time step $\Delta t$ is taken to be 2 months. First, we show the coseismic slip distribution in Fig. 3a, where the contour intervals are $3 \mathrm{~m}$. The spatial pattern of coseismic slip with a main rupture area off Miyagi and a sub-rupture area off Fukushima is consistent with those by Ozawa et al. (2011) and Hashimoto et al. (2012), which were estimated only from GPS data on land, but not with those by Ozawa et al. (2012) and Iinuma et al. (2012), which were estimated from both GPS data on land and GPS/ Acoustic data on seafloor. The estimated maximum slip of $22 \mathrm{~m}$ and the calculated seismic moment of $3.2 \times 10^{22} \mathrm{Nm}\left(\mathrm{M}_{\mathrm{w}} 8.9\right)$ are comparable to those by Ozawa et al. (2011) and Hashimoto et al. (2012).

A series of diagrams, Fig. $3 b-h$, show the temporal variation of cumulative afterslip distribution from the 12th March 2011 to the 11th September 2014, where the contour intervals are $2 \mathrm{~m}$. The spatial pattern of afterslip with maximum beneath the Iwate and Miyagi coastal regions hardly changes with time. That is to say, the afterslip has mainly proceeded at the downdip extension of the main rupture. This is a characteristic common to most of the preceding studies (Ozawa et al. 2012; Diao et al. 2014; Yamagiwa et al. 2015) except Perfettini and Avouac (2014). The point at issue will be whether significant afterslip has occurred or not in a shallow part of the plate interface, which gives a key to understanding the frictional property of plate interfaces in subduction zones. For example, the result of inversion analysis by Perfettini and Avouac (2014) shows a dominant zone of shallow afterslip extending over the main rupture area near the trench. Sun and Wang (2015) have suggested the existence of large shallow afterslip outside of the main rupture area. Yamagiwa 
(a) $2011 / 03 / 11$

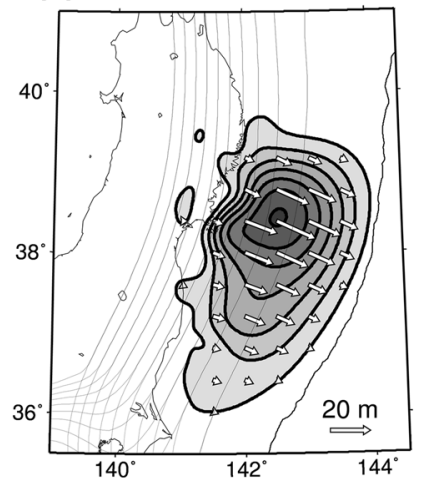

(e) $2011 / 03 / 12-2013 / 03 / 11$

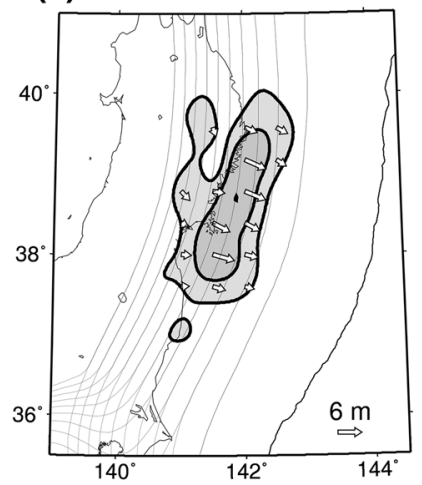

(b) $2011 / 03 / 12-2011 / 09 / 11$

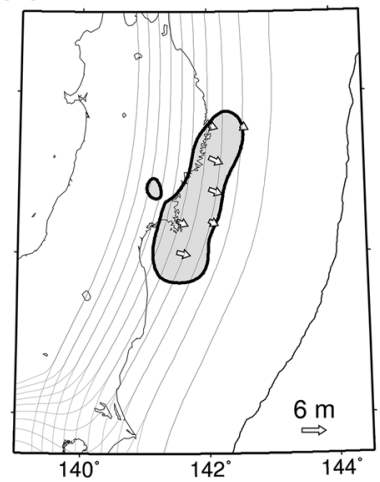

(f) $2011 / 03 / 12-2013 / 09 / 11$

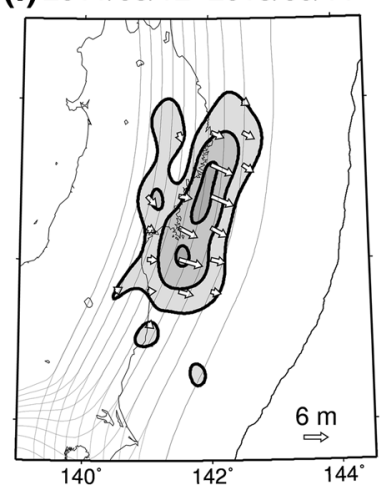

(c) $2011 / 03 / 12-2012 / 03 / 11$

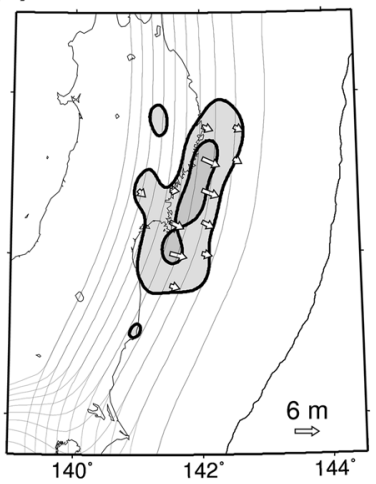

(d) $2011 / 03 / 12-2012 / 09 / 11$

(g) $2011 / 03 / 12-2014 / 03 / 11$

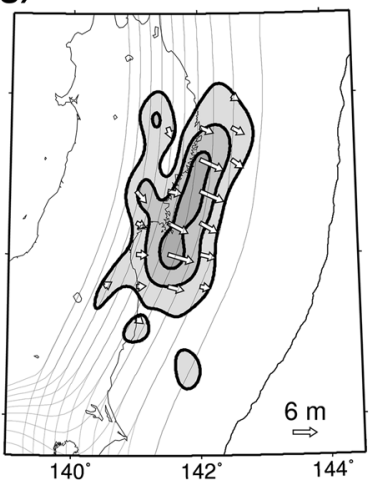

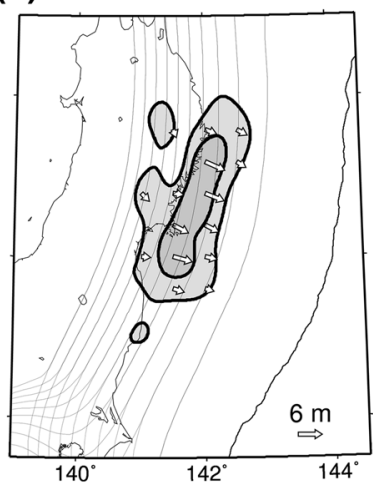

(h) $2011 / 03 / 12-2014 / 09 / 11$

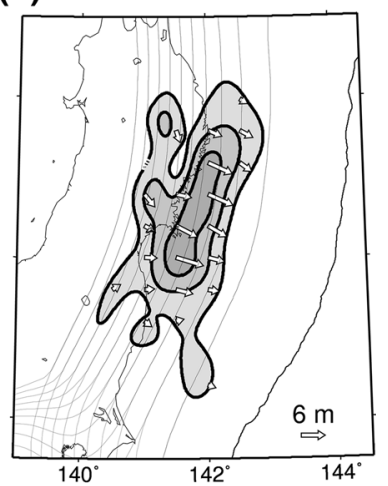

Figure 3

Coseismic slip distribution and the subsequent afterslip evolution estimated from GPS data on land. a Coseismic slip distribution of the 2011 Tohoku-oki earthquake on the plate interface. The contour intervals are $3 \mathrm{~m}$. The gray arrows indicate coseismic slip vectors. b-h Snapshots of cumulative afterslip distribution every 6 months from the 12th March 2011 to the 11th September 2014. The contour intervals are $2 \mathrm{~m}$. The gray arrows indicate cumulative afterslip vectors. In each diagram, the plate interface is shown by the gray iso-depth contours at the interval of $10 \mathrm{~km}$

et al. (2015) have also stated that significant afterslip occurred in a shallow part of the plate interface off Fukushima, the northern half of which overlaps with the main rupture area. On the other hand, our present result as well as the results by Ozawa et al. (2012) and Diao et al. (2014) do not show the existence of any significant shallow afterslip.

In Fig. 4a, b, we plot the cumulative moment of afterslip and interplate aftershocks, respectively, against the time after the main rupture. The moment release by aftershocks decays very soon, and its amount is negligible (one order of magnitude smaller) in comparison with afterslip. The afterslip has rapidly proceeded for the first 1 year after the main rupture. The rate of moment release by afterslip seems to be almost constant after this period. The total amount of moment release by afterslip for the first 3.5 years is $1.3 \times 10^{22} \mathrm{Nm}\left(\mathrm{M}_{\mathrm{w}} 8.7\right)$, which is about one third of that by the coseismic slip.

\section{Postseismic Offshore Crustal Movements}

From the coseismic and postseismic slip distributions estimated in Sect. 3, we computed postseismic offshore horizontal movements using Eq. (11), and compared them with the seafloor GPS/ Acoustic observations reported by Watanabe et al. (2014), which we did not use for the present inversion analysis. First, we show the spatial patterns of elastic part and viscoelastic relaxation part of the postseismic horizontal movements in Fig. 5a, b, respectively. 

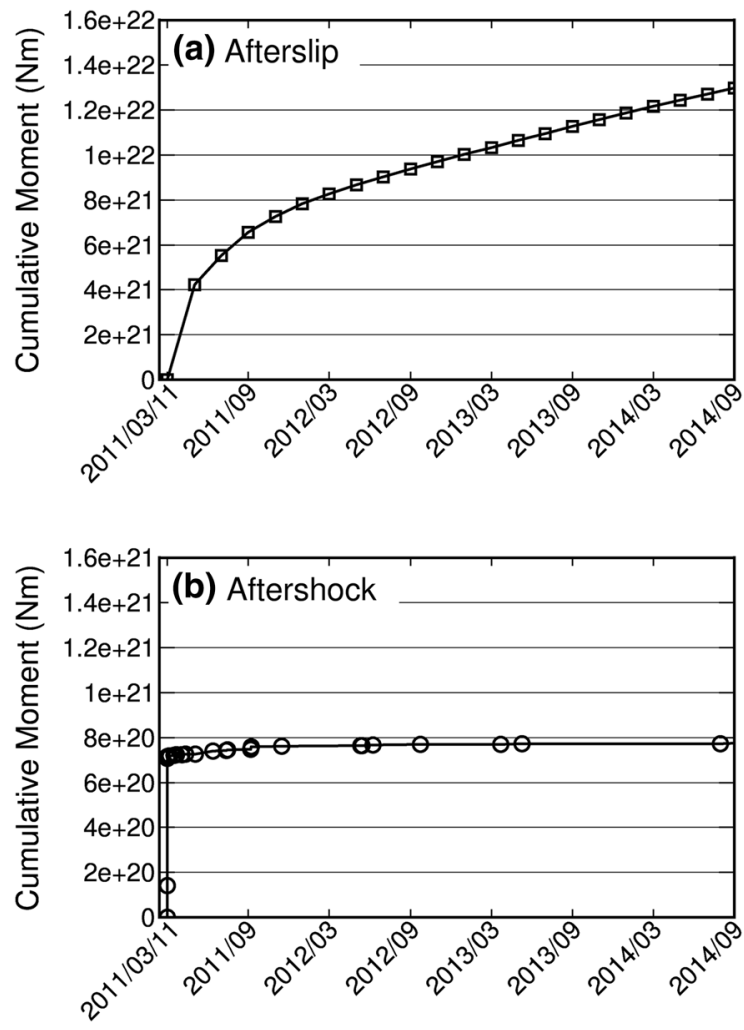

Figure 4

Temporal change of moment release after the 2011 Tohoku-oki earthquake. a The cumulative moment of afterslip. b The cumulative moment of aftershocks

Here, Fig. 5a shows only the elastic response to cumulative afterslip for a period from the 12th March 2011 to the 11th January 2014, which corresponds to the period of GPS/Acoustic observation. Figure 5b shows only the cumulative effect of viscoelastic stress relaxation for the same period. From Fig. 5a, we can see large trench-ward displacements in the inshore region and small landward displacements in the offshore region. From Fig. 5b, on the other hand, we can see overall landward displacements with a broad peak just above the main rupture area.

The spatial pattern of elastic responses to afterslip in Fig. 5a can be rationally explained by the dominant afterslip at a high-angle downdip extension of the main rupture. As shown in Fig. 6, the coseismic slip of the Tohoku-oki earthquake occurred on the low-angle offshore plate interface, while the dominant afterslip proceeded on the high-angle inshore plate interface. The high-angle afterslip fault (red
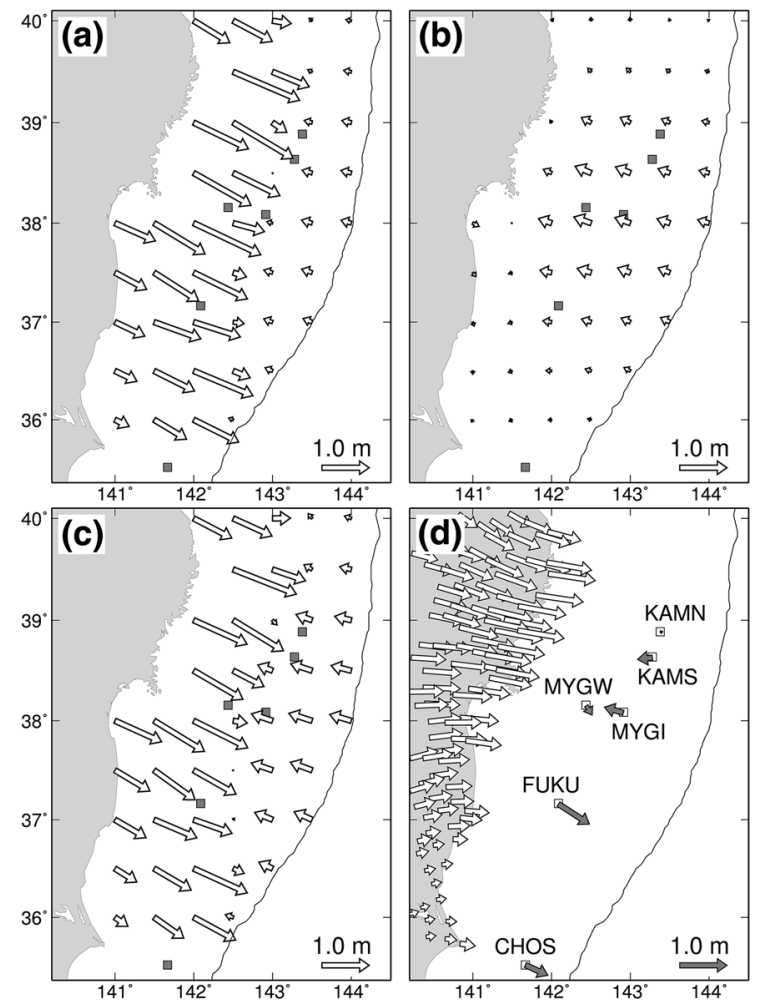

Figure 5

Spatial patterns of observed and computed postseismic horizontal displacements for the period of 2011/03/12-2014/01/11. a Cumulative elastic responses to afterslip. b Cumulative effects of viscoelastic stress relaxation. $\mathbf{c}$ Horizontal displacements obtained by adding a and b. d Observed displacements on land (white arrows) and seafloor (gray arrows). The solid squares in ac correspond to GPS/Acoustic stations in d

solid line) and its updip extension (red broken line) divide the elastic surface layer into the hanging wall and footwall. The horizontal displacements due to afterslip (reverse dip slip) are generally trench-ward on the hanging-wall side and landward on the footwall side. In the present case, the updip extension of the high-angle afterslip fault intersects the earth's surface at a point between the GPS/Acoustic stations MYGW and MYGI. This is the reason behind the discontinuous change of horizontal movements from trench-ward to landward.

In Fig. 5c, we show the total horizontal displacements obtained by adding the elastic responses to afterslip in Fig. 5a and the effects of viscoelastic relaxation in Fig. 5b, which can be directly compared with the seafloor GPS/Acoustic observations in Fig. 5d. From Fig. 5c, we can see that the effects of 


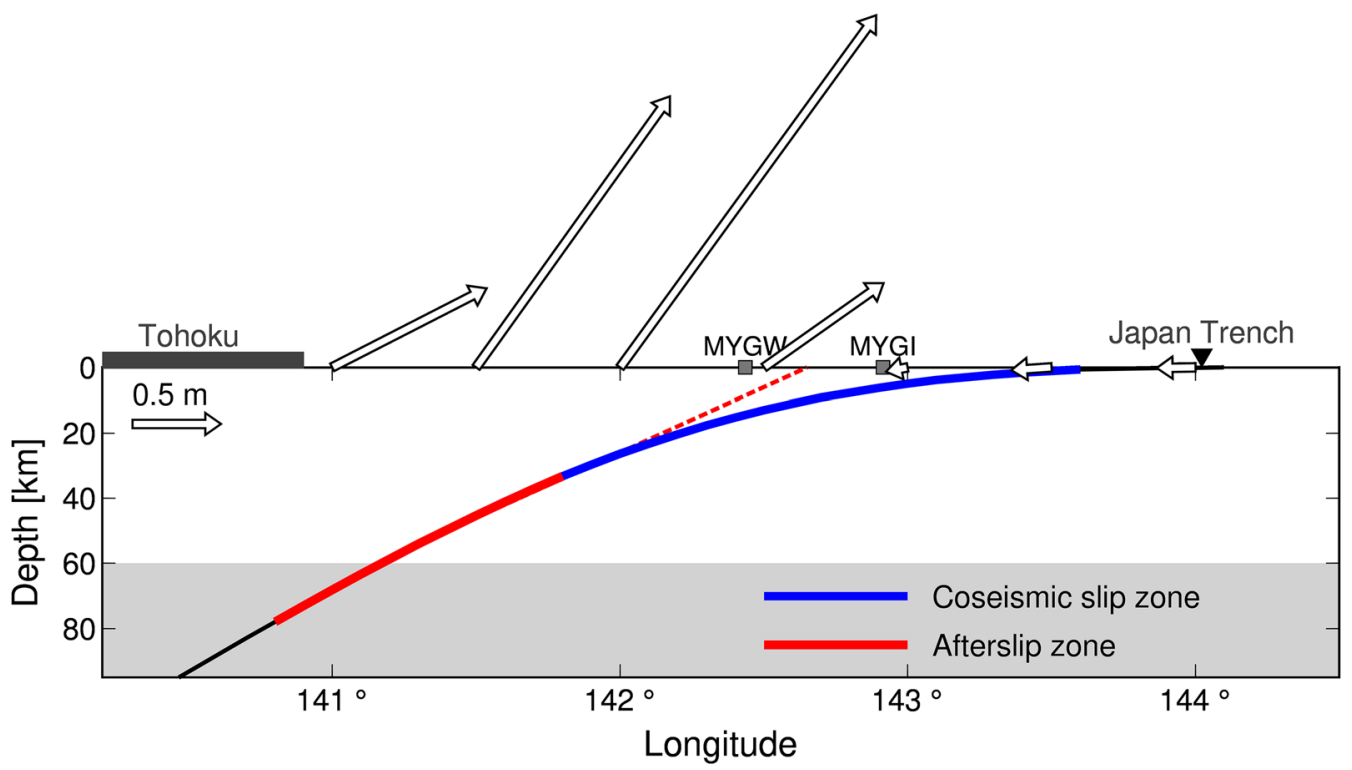

Figure 6

Surface displacements due to afterslip on the high-angle downdip extension of the coseismic slip zone. The vertical section of Fig. 5a at $38.0^{\circ} \mathrm{N}$ is shown. The blue and red sections of the plate interface represent the coseismic slip and afterslip zones of the 2011 Tohoku-oki earthquake, respectively. The red broken line indicates the updip extension of the high-angle afterslip fault. MYGW and MYGI are the codes of GPS/Acoustic stations

viscoelastic stress relaxation in the asthenosphere suppress the trench-ward movements on the hangingwall side and enhance the landward movements on the footwall side. The spatial pattern of the total horizontal displacements is consistent with the seafloor GPS/Acoustic observations as a whole. From Fig. 5d, we can see that the postseismic horizontal movements at KAMS and MYGI on the footwall side are landward, and those at FUKU and CHOS on the hanging-wall side are trench-ward. The horizontal displacement observed at MYGW, which is located at the tip of the hanging wall, is trench-ward but very small. This is well explained by the composite effect of the trench-ward movement due to afterslip and the landward movement due to viscoelastic relaxation.

The elastic responses to afterslip and the effects of viscoelastic relaxation are essentially different not only in spatial pattern but also in temporal change. In Fig. 7, we show the temporal changes of observed and computed postseismic horizontal movements at three representative GPS/Acoustic stations, MYGI, MYGW and FUKU. From the calculation results shown in the lower half of Fig. 7, we can see that the elastic responses to afterslip (open squares) decay soon with the time constant of about 1 year, while the effects of viscoelastic relaxation (open triangles) almost linearly increase with time for the first 3 years after the main rupture. Then, the relative weight of these two elements controls the transient behavior of postseismic horizontal movement (open circle) at each station. For instance, at MYGI the effect of viscoelastic relaxation is dominant, at FUKU the elastic response to afterslip is dominant, and at MYGW the elastic response to afterslip and the effect of viscoelastic relaxation cancel each other out. General agreement between the computed horizontal movements and the seafloor GPS/Acoustic observations, shown in the upper half of Fig. 7, demonstrates that the postseismic curious seafloor crustal movements were caused by the combined effect of afterslip on a high-angle downdip extension of the main rupture and viscoelastic stress relaxation in the asthenosphere. 

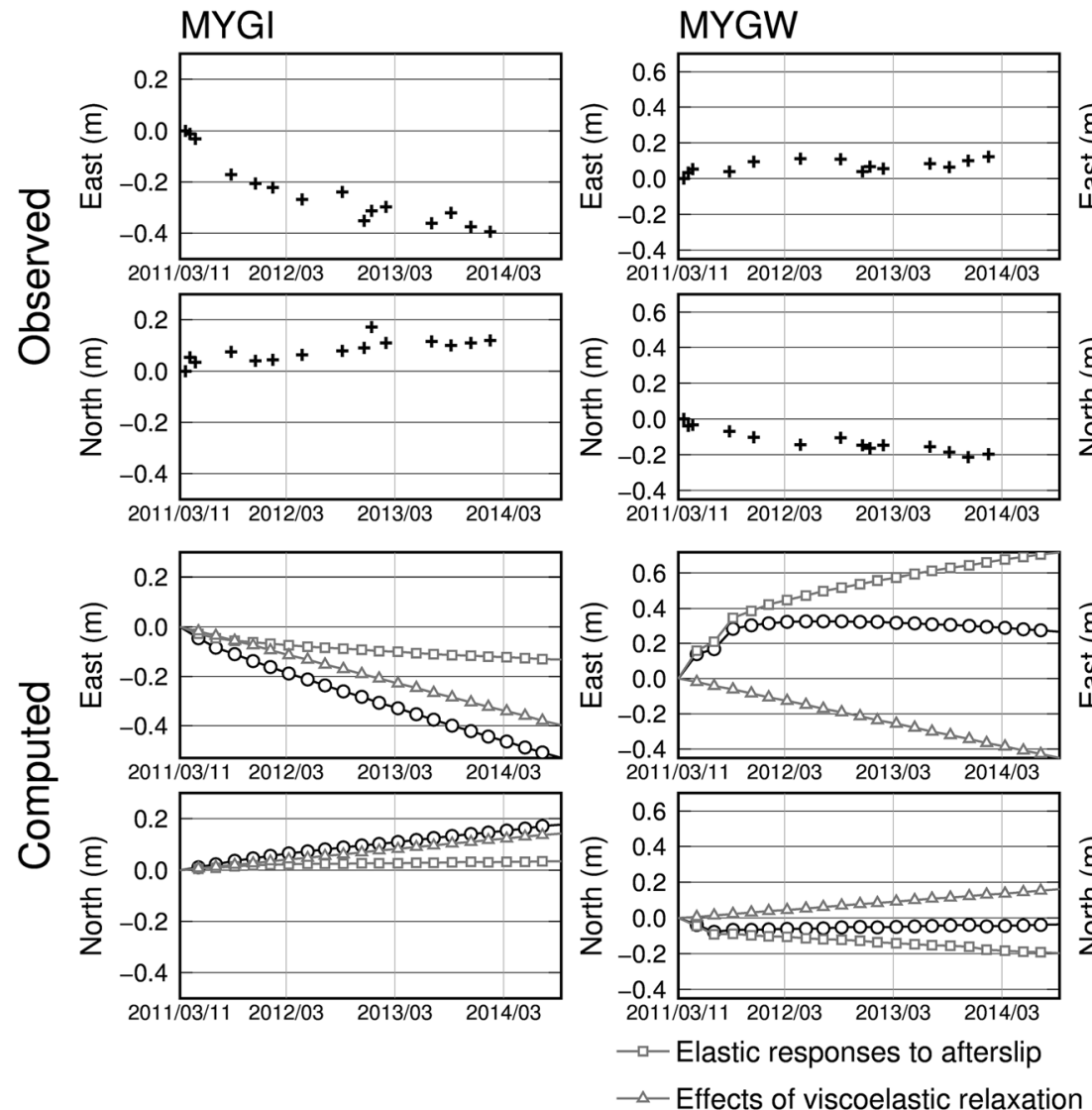
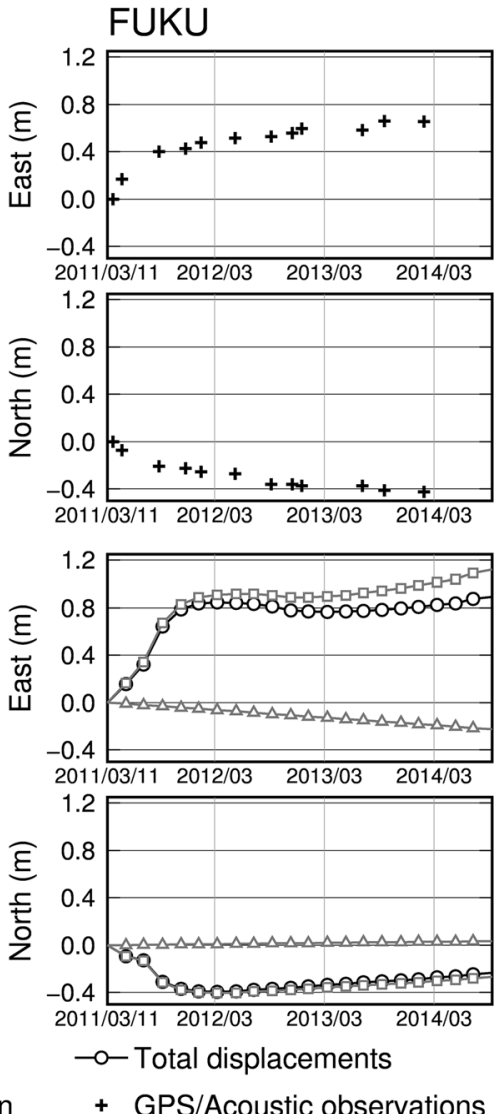

Figure 7

Temporal changes of observed and computed postseismic horizontal movements. Upper half: Observed horizontal displacements at the seafloor GPS/Acoustic stations, MYGI, MYGW and FUKU (Watanabe et al. 2014). Lower half: Computed horizontal displacements. The open squares, triangles, and circles represent elastic responses to afterslip, effects of viscoelastic relaxation, and the sum of them (total displacements), respectively

\section{Discussion}

In this study, to reveal the cause of the curious offshore crustal movements observed after the 2011 Tohoku-oki megathrust earthquake, we analyzed the coseismic and postseismic GPS time-series data on land with a sequential stepwise inversion method considering the viscoelastic stress relaxation in the asthenosphere. Interplate megathrust events, such as the Tohoku-oki earthquake, generally cause large stress concentrations at the tips of main ruptures and non-negligible stress changes not only in the elastic lithosphere but also in the viscoelastic asthenosphere. The stress concentrations are eventually released by aftershocks in a shallow brittle zone and afterslip in a deep brittle-ductile transition zone. The stress changes in the asthenosphere vanish sooner or later because of their viscoelastic relaxation. The moment release by aftershocks is smaller by one order magnitude than that by afterslip as shown in Fig. 4. Then, the main cause of postseismic crustal movements is considered to be afterslip at the plate interface and viscoelastic stress relaxation in the asthenosphere.

Crustal responses to afterslip and viscoelastic stress relaxation are essentially different both in space and time. So, it is possible to estimate the spatiotemporal distribution of afterslip from observed postseismic crustal movements by using a proper inversion method. In addition, to obtain unbiased results of the inversion analysis, we need to use (1) proper plate interface geometry, (2) proper crustmantle rheological structure, and also (3) a consistent 
coseismic slip distribution, which causes coseismic stress changes in the asthenosphere. Diao et al. (2014) and Yamagiwa et al. (2015) as well as the present study performed simultaneous inversion for coseismic and postseismic slip distributions with a standard crust-mantle rheological structure model to satisfy the second and third requirements, but Sun and Wang (2015) and Hu et al. (2016) did not.

In our common understanding, as mentioned above, afterslip is considered to occur in a deep brittle-ductile transition zone so as to release the stress concentrations caused at the tip of main rupture. Then, we need to examine the validity of estimation results from such a point of view. In Fig. 8, we plot the locations of the estimated coseismic slip zone (indicated by black contours) and main afterslip zone (indicated by thick gray contours) together with the locations of large interplate aftershocks $\left(M_{w} \geq 6.0\right)$ for the first 3.5 years after the

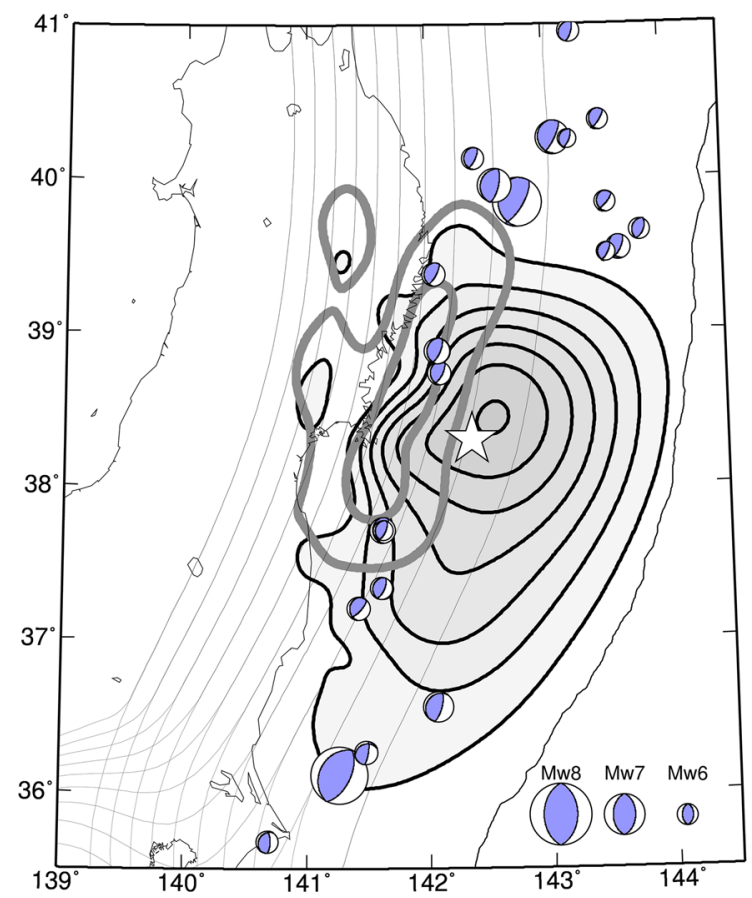

Figure 8

Spatial distributions of the coseismic slip, cumulative afterslip, and interplate aftershocks associated with the 2011 Tohoku-oki earthquake. The distribution of coseismic slip is shown by the black contours at the intervals of $3 \mathrm{~m}$. The distributions of cumulative afterslip and large interplate aftershocks $\left(M_{w} \geq 6.0\right)$ for the first 3.5 years after the main shock are shown by the thick gray contours at the intervals of $3 \mathrm{~m}$ and the focal spheres with their size proportional to $\mathrm{M}_{\mathrm{w}}$, respectively
Tohoku-oki earthquake. From this figure, we can see that the stresses concentrated at the tip of main rupture were certainly released by aftershocks in a shallow brittle zone and afterslip in a deep brittleductile transition zone. In the case of Diao et al. (2014), the eastern half of the deep afterslip area overlaps with the western half of the shallow main rupture area. In contrast, in the case of Yamagiwa et al. (2015), there exists a significant gap between the deep afterslip area and the shallow main rupture area. In either case, some rational explanation would be needed for justifying the estimation results.

One of the causes for the difference in estimation results between the present study and Yamagiwa et al. (2015) may be in the difference of the data sets used for inversion analysis: the former used GPS data only, while the latter used both GPS data and seafloor GPS/Acoustic data. Another cause may be in the difference of the plate interface geometries used for inversion analysis. We plot the vertical sections of the NAM-PAC plate interface off Miyagi (Hashimoto et al. 2004; Miura et al. 2005; Nakajima and Hasegawa 2006; Hayes et al. 2012) used for estimating the coseismic slip and afterslip distributions of the 2011 Tohoku-oki earthquake in Fig. 9, where the blue line gives a reference geometry, which was deduced from a wide-angle reflection and refraction study. For example, the present study as well as Hashimoto et al. (2012) used the plate interface model by Hashimoto et al. (2004), while Yamagiwa et al. (2015) as well as Ozawa et al. (2011, 2012) and Iinuma et al. (2012) used the plate interface model by Nakajima and Hasegawa (2006). The model by Hashimoto et al. (2004) is very close to the reference geometry, but significantly different in dip-angle at the depths from the model by Nakajima and Hasegawa (2006). In the case of Yamagiwa et al. (2015) with the NakajimaHasegawa plate interface model, the updip extension of the dominant afterslip fault intersects the earth's surface at a point about 50-km east off MYGI. So, the discontinuous change of horizontal movements from trench-ward to landward as shown in Fig. 6 does not occur at any point between MYGW and MYGI. Conversely, the systematic error of plate interface geometry would lead to some bias in the estimation of not only afterslip but also coseismic slip distribution. 


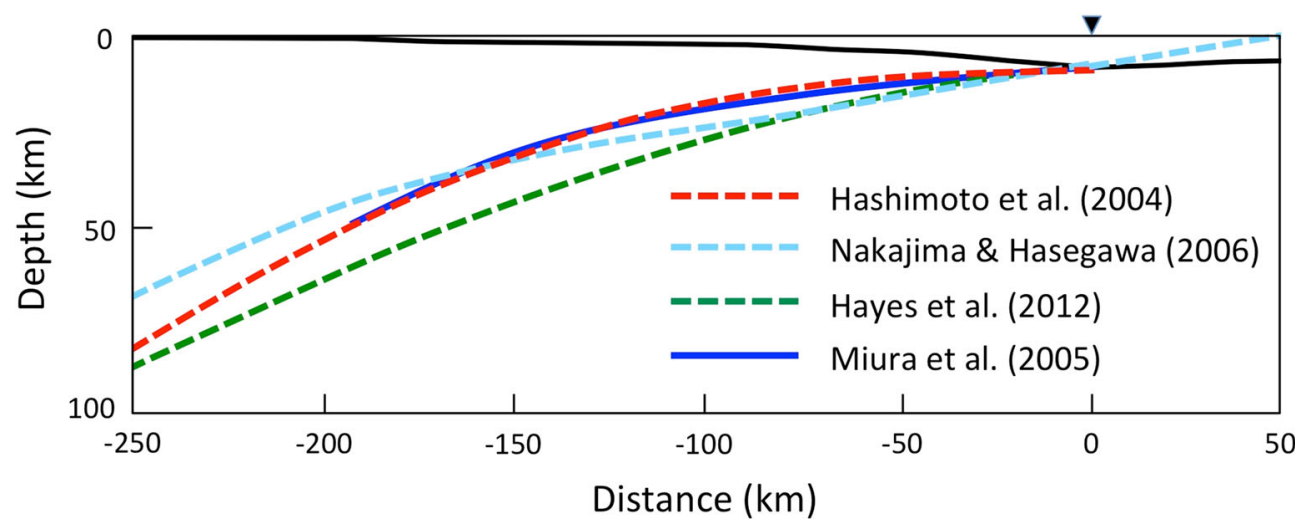

Figure 9

The vertical sections of the NAM-PAC plate interface off Miyagi used for estimating the coseismic slip and afterslip distributions of the 2011 Tohoku-oki earthquake. The blue line gives a reference geometry, which was deduced from a wide-angle reflection and refraction study

\section{Conclusions}

Transient crustal movements following the 2011 Tohoku-oki megathrust earthquake were clearly observed by a dense GPS network (GEONET) on land and a sparse GPS/Acoustic positioning network on seafloor. The postseismic offshore crustal movements seems to be curious; slowly decaying landward movements above the main rupture area and rapidly decaying trench-ward movements in its southern extension. To reveal the cause of such curious offshore crustal movements, we analyzed the coseismic and postseismic GPS array data on land with a sequential method of stepwise inversion considering viscoelastic stress relaxation in the asthenosphere, and obtained the following results. The afterslip of the Tohoku-oki earthquake has rapidly proceeded for the first 1 year at a high-angle downdip extension of the main rupture on the low-angle offshore plate interface. The theoretical patterns of postseismic horizontal movements due to the afterslip and the viscoelastic stress relaxation in the asthenosphere are essentially different both in space and time; inshore trench-ward movements and offshore landward movements for the afterslip, while overall landward movements for the viscoelastic stress relaxation. General agreement between the computed horizontal movements and the GPS/Acoustic observations demonstrates that the postseismic curious offshore crustal movements can be ascribed to the combined effect of afterslip on a high-angle downdip extension of the main rupture and viscoelastic stress relaxation in the asthenosphere.

\section{Acknowledgements}

We thank two anonymous reviewers for their useful comments and suggestions to improve the manuscript. We used the daily coordinate data of GPS stations (GEONET F3-Solution) published by the Geospatial Information Authority of Japan (GSI). The computer program developed by Fukahata and Matsu'ura (2006) was used for evaluating viscoelastic slip-response functions. For plotting, we used the Generic Mapping Tools (Wessel and Smith 1998). This study was partly supported by research funds from the Japan Atomic Power Company and the National Research Institute for Earth Science and Disaster Resilience (Research project "Large Earthquake Generation Process").

Open Access This article is distributed under the terms of the Creative Commons Attribution 4.0 International License (http:// creativecommons.org/licenses/by/4.0/), which permits unrestricted use, distribution, and reproduction in any medium, provided you give appropriate credit to the original author(s) and the source, provide a link to the Creative Commons license, and indicate if changes were made. 


\section{REFERENCES}

Akaike, H. (1974). A new look at the statistical model identification. IEEE Transactions on Automatic Control, 19, 716-723.

Akaike, H. (1980). Likelihood and Bayes procedure. In J. M. Bernardo, M. H. DeGroot, D. V. Lindley, \& A. F. M. Smith (Eds.), Bayesian statistics (pp. 143-166). Valencia: Valencia University Press.

Diao, F., Xiong, X., Wang, R., Zheng, Y., Walter, T. R., Weng, H., et al. (2014). Overlapping post-seismic deformation processes: Afterslip and viscoelastic relaxation following the $2011 \mathrm{Mw} 9.0$ Tohoku (Japan) earthquake. Geophysical Journal International, 196, 218-229.

Fukahata, Y., \& Matsu'ura, M. (2006). Quasi-static internal deformation due to a dislocation source in a multilayered elastic/ viscoelastic half-space and an equivalence theorem. Geophysical Journal International, 166, 418-434.

Hashima, A., Fukahata, Y., Hashimoto, C., \& Matsu'ura, M. (2014). Quasi-static strain and stress fields due to a moment tensor in elastic-viscoelastic layered half-space. Pure and Applied Geophysics, 171, 1669-1693.

Hashimoto, C., Fukui, K., \& Matsu'ura, M. (2004). 3-D modelling of plate interfaces and numerical simulation of long-term crustal deformation in and around Japan. Pure and Applied Geophysics, 161, 2053-2067.

Hashimoto, C., Noda, A., \& Matsu'ura, M. (2012). The Mw9.0 northeast Japan earthquake: Total rupture of a basement asperity. Geophysical Journal International, 189, 1-5.

Hayes, G. P., Wald, D. J., \& Johnson, R. L. (2012). Slab1.0: A three-dimensional model of global subduction zone geometries. Journal of Geophysical Research, 117, B01302. doi:10.1029/ 2011 JB008524.

Hu, Y., Bürgmann, R., Uchida, N., Banerjee, P., \& Freymueller, J. T. (2016). Stress-driven relaxation of heterogeneous upper mantle and time-dependent afterslip following the 2011 Tohoku earthquake. Journal of Geophysical Research: Solid Earth, 121, 385-411.

Iinuma, T., Hino, R., Kido, M., Inazu, D., Osada, Y., Ito, Y., et al. (2012). Coseismic slip distribution of the 2011 off the Pacific Coast of Tohoku Earthquake (M9.0) refined by means of seafloor geodetic data. Journal of Geophysical Research, 117, B07409. doi:10.1029/2012JB009186.

Lubis, A. M., Hashima, A., \& Sato, T. (2013). Analysis of afterslip distribution following the 2007 September 12 southern Sumatra earthquake using poroelastic and viscoelastic media. Geophysical Journal International, 192, 18-37.

Matsu'ura, M., Noda, A., \& Fukahata, Y. (2007). Geodetic data inversion based on Bayesian formulation with direct and indirect prior information. Geophysical Journal International, 171, 1342-1351.

Matsu'ura, M., \& Iwasaki, T. (1983). Study on coseismic and postseismic crustal movements associated with the 1923 Kanto earthquake. Tectonophysics, 97, 201-215.

Miura, S., Takahashi, N., Nakanishi, A., Tsuru, T., Kodaira, S., \& Kaneda, Y. (2005). Structural characteristics off Miyagi forearc region, the Japan Trench seismogenic zone, deduced from a wideangle reflection and refraction study. Tectonophysics, 407, 165-188.
Muto, J., Shibazaki, B., Iinuma, T., Ito, Y., Ohta, Y., Miura, S., et al. (2016). Heterogeneous rheology controlled postseismic deformation of the 2011 Tohoku-Oki earthquake. Geophysical Research Letters, 43, 4971-4978. doi:10.1002/2016GL068113.

Nakajima, J., \& Hasegawa, A. (2006). Anomalous low-velocity zone and linear alignment of seismicity along it in the subducted Pacific slab beneath Kanto, Japan: Reactivation of subducted fracture zone? Geophysical Research Letters, 33, L16309. doi:10.1029/2006GL026773.

Noda, A., Hashimoto, C., Fukahata, Y., \& Matsu'ura, M. (2013). Interseismic GPS strain data inversion to estimate slip-deficit rates at plate interfaces: application to the Kanto region, central Japan. Geophysical Journal International, 193, 61-77.

Ohzono, M., Yabe, Y., Iinuma, T., Ohta, Y., Miura, S., Tachibana, K., et al. (2012). Strain anomalies induced by the 2011 Tohoku Earthquake (Mw 9.0) as observed by a dense GPS network in northeastern Japan. Earth Planets Space, 64, 1231-1238.

Ozawa, S., Nishimura, T., Munekane, H., Suito, H., Kobayashi, T., Tobita, M., et al. (2012). Preceding, coseismic, and postseismic slips of the 2011 Tohoku earthquake, Japan. Journal of Geophysical Research, 117, B07404. doi:10.1029/2011JB009120.

Ozawa, S., Nishimura, T., Suito, H., Kobayashi, T., Tobita, M., \& Imakiire, T. (2011). Coseismic and postseismic slip of the 2011 magnitude-9 Tohoku-oki earthquake. Nature, 475, 373-376.

Perfettini, H., \& Avouac, J. P. (2014). The seismic cycle in the area of the 2011 Mw9.0 Tohoku-Oki earthquake. Journal of Geophysical Research: Solid Earth, 119, 4469-4515.

Sato, M., Ishikawa, T., Ujihara, N., Yoshida, S., Fujita, M., \& Asada, A. (2011). Displacement above the hypocenter of the 2011 Tohoku-oki earthquake. Science, 332, 1395.

Suito, H. (2017). Importance of rheological heterogeneity for interpreting viscoelastic relaxation caused by the 2011 TohokuOki earthquake. Earth Planets Space, 69, 21. doi:10.1186/ s40623-017-0611-9.

Sun, T., \& Wang, K. (2015). Viscoelastic relaxation following subduction earthquakes and its effects on afterslip determination. Journal of Geophysical Research: Solid Earth, 120, 1329-1344.

Sun, T., Wang, K., Iinuma, T., Hino, R., He, J., Fujimoto, H., et al. (2014). Prevalence of viscoelastic relaxation after the 2011 Tohoku-oki earthquake. Nature, 514, 84-87.

Takada, Y., \& Fukushima, Y. (2013). Volcanic subsidence triggered by the 2011 Tohoku earthquake in Japan. Nature Geoscience, 6, 637-641.

Watanabe, S., Sato, M., Fujita, M., Ishikawa, T., Yokota, Y., Ujihara, N., et al. (2014). Evidence of viscoelastic deformation following the 2011 Tohoku-Oki earthquake revealed from seafloor geodetic observation. Geophysical Research Letters, 41, 5789-5796.

Wessel, P., \& Smith, W. H. F. (1998). New, improved version of the generic mapping tools released. EOS Transactions American Geophysical Union, 79, 579.

Yamagiwa, S., Miyazaki, S., Hirahara, K., \& Fukahata, Y. (2015). Afterslip and viscoelastic relaxation following the 2011 Tohokuoki earthquake (Mw9.0) inferred from inland GPS and seafloor GPS/Acoustic data. Geophysical Research Letters, 42, 66-73.

(Received May 31, 2017, revised September 22, 2017, accepted September 25, 2017, Published online October 6, 2017) 